\title{
La cesión de créditos en el código civil peruano: críticas fundamentales
}

\author{
The assignment of credits in the Peruvian Civil Code: \\ fundamental criticisms
}

\author{
Cesar Arturo Ayllón Valdivia ${ }^{1^{*}}$ \\ ${ }^{1}$ Universidad Continental, Facultad de Derecho
}

\section{RESUMEN}

Cuando las partes contratantes deciden realizar la cesión de créditos nos encontramos ante varios inconvenientes como son determinar: si mediante la cesión de créditos podemos transferir otros derechos, si estamos ante un acto de obligación o un acto de disposición, a quién debe preferirse en el caso de concurrencia de acreedores cuando se realiza más de una cesión sobre el mismo derecho, entre otros temas controversiales que trataremos en este trabajo. Si bien esta institución ha sido ampliamente tratada en la doctrina jurídica y sus fundamentos revisten singular importancia para nuestra sociedad, al igual que muchas de las instituciones del Código Civil peruano, los verdaderos alcances de la cesión de créditos resultan aún de difícil comprensión. A través de este estudio, doctrinario y legal, pretendemos mostrar algunas de las graves deficiencias que presenta esta institución en el Código Civil peruano, que al igual que otros ordenamientos, no ha logrado darle un tratamiento sistemático, obligándonos a buscar respuestas en gran variedad de doctrinas que pugnan por imponerse, pero sin llegar a consolidarse como el fundamento para una regulación coherente que incentive la contratación mediante un ordenamiento claro y preciso. Una de las conclusiones manifiesta que en el régimen legal peruano, para la transferencia de una cosa, el contrato de compraventa sería el título de adquisición y la entrega (cosas muebles) o la concurrencia del artículo 949 del Código Civil peruano (cosas inmuebles) sería el modo de adquirir.

Palabras clave: Compraventa, cesión de créditos, bienes, transferencia de propiedad, concurrencia de acreedores

\begin{abstract}
When the contracting parties decide to make the assignment of credits we have several disadvantages , such as: if through the assignment of credits we can transfer other rigths, if we are facing an act of obligation or an act of disposition, who should be preferred in the case of concurrence of creditors when more than one assignment is made on the same right, among other controversial issues that we will deal with in this work. Although this institution has been widely treated in the legal doctrine and its foundations are of singular importance for our society, like many of the institutions of the Peruvian Civil Code, the true scope of the assignment of credits is still difficult to understand. Through this doctrinal and legal study, we intend to show some of the serious deficiencies that this institution presents in the Peruvian Civil Code which, like other legal systems, has not managed to give it a systematic treatment, forcing us to seek answers in a wide variety of ways doctrines that struggle to impose themselves, but without becoming consolidated as the basis for a coherent regulation that encourages hiring through a clear and precise ordering. One of the conclusions states that in the peruvian legal regime, for the transfer of a thing, the purchase contract would be the acquisition title and the delivery (movable things) or the concurrence of article 949 of the Peruvian Civil Code (real property) would be the way to acquire.
\end{abstract}

Keywords: Purchase, assignment of credits, assets, transfer of property, concurrence of creditors.

Historial del artículo:

Recibido, 03 de octubre de 2017; aceptado, 22 de diciembre de 2017; disponible en línea, 05 de enero de 2018

* Abogado, Magister en Finanzas y Derecho Corporativo, docente de la Universidad Continental.

Correo: cayllon@continental.edu.pe 


\section{INTRODUCCIÓN}

\section{¿Cesión de créditos o de derechos?}

En el Código civil peruano de 1936 la Cesión de Créditos era un contrato típico allí regulado, por el cual el cedente se obligaba a transferir al cesionario la propiedad de un derecho de crédito.

"Artículo 1456.- "El acreedor puede ceder su crédito, si a ello no se opone la naturaleza de la obligación, la ley o la convención del deudor".

"Artículo 1457.- "No adquiere el cesionario acción contra el deudor cedido por los derechos que se le hubiere trasferido, sino desde que éste acepta la traslación, o desde que se le notifica judicialmente".

Se pretendía así, dar un carácter autónomo a la cesión. La compraventa, por su parte, era el contrato que tenía como objeto la transferencia a título oneroso de la titularidad de una situación jurídica específica, la propiedad de cosas. Para la transferencia de otras situaciones jurídicas distintas a la propiedad de cosas (entre ellas el crédito) estaba la cesión de créditos.

En esta línea de opinión coincide Borda (1973), al considerar que la cosa debe tratarse de un objeto material susceptible de apreciación económica. Si por el contrario se enajena un derecho habrá cesión de derechos pero no una compraventa. Sin embargo, menciona que en el derecho moderno se tiende a considerar la enajenación de cosas o derechos susceptibles de apreciación económica (pp. 182185). Asimismo, Lorenzetti (2004) considera que la cesión de derechos "es aquel contrato mediante el cual una de las partes transfiere a la otra un derecho, con lo cual se deja abierta la posibilidad de que existan modalidades diferentes tanto por el tipo de derechos (personales, reales, intelectuales, litigiosos, etc.), por la causa fuente (cesión venta, permuta, donación), o por la finalidad (traslativa, garantía, fiduciaria)" (p. 40).

No obstante, el contrato de cesión de créditos se confundía con otros contratos cuya función era transferir la titularidad de la propiedad de cosas: como la compraventa, la donacion o la permuta. Así, por ejemplo, se decía que había cesión-venta, si la cesión se realizaba a cambio de un precio en dinero, cesióndonación, si era gratuita, y cesión- permuta si era por otro crédito.

Si bien no es el propósito de este trabajo profundizar en el análisis de este tema, nos limitaremos a exponer algunas de las posturas que se han propuesto en torno a la concepción del "bien" o "cosa" a fin de establecer su íntima relación con la cesión de créditos y los contratos que transfieren propiedad de bienes, entre ellos, el contrato de compraventa.
Así, a juzgar por los Mazeaud et al (1959): "El objeto de la compraventa puede ser, con exclusión de los derechos de la personalidad, que no podrían ser cedidos, un derecho patrimonial cualquiera (...) Casi siempre, la transmisión, que se efectúa del vendedor al comprador, concierne al derecho de propiedad. Es sabido que, en el lenguaje corriente, y hasta en el de los juristas, el derecho de propiedad se confunde con la cosa sobre la cual recae (...). Por ser la compraventa del derecho de propiedad, entre todas las compraventas, la más corriente, se ha implantado la costumbre de reservarle la denominación de "compraventa", y designar con la palabra "cesión" a la compraventa de otro derecho. Al reglamentar la compraventa, los redactores del Código civil no pensaron, por otro lado, sino en la compraventa de una cosa, o sea, del derecho de propiedad (...). Sin embargo, la compraventa puede recaer, sobre otro derecho real; la cesión de un derecho de usufructo, por ejemplo, es una compraventa" (p. 15).

En esta línea también, Lete entiende que "pueden ser objeto del contrato de compraventa todas las cosas, tanto las corporales como las incorporales, así como los derechos" Lete del Rio (1990, p. 25).

Considera Diez Picazo que, por regla general, pueden ser objeto del contrato de compraventa tanto las cosas corporales como incorporales, específicas y genéricas, Diez Picazo et al (1980, pp. 232-234).

Sostiene Peirano (1997) que “(...) el objeto de la compraventa puede ser tanto corporal como incorporal (derecho)" (p. 261).

Comenta Rezzónico (1967) que: "Para completar el concepto de cosa, creemos oportuno transcribir el siguiente párrafo tomado de un pasaje jurisprudencial: "Las cosas materiales de existencia física y real, son las que caen inmediatamente bajo nuestros sentidos en cualquiera de sus tres estados; sólido, líquido o gaseoso, a diferencia de las cosas inmateriales, de existencia jurídica reales, de existencia jurídica y legal, que sólo se perciben por nuestra inteligencia". Ambas categorías, las cosas materiales como inmateriales pueden ser objeto del contrato de compraventa" ( $p$. 183).

Al respecto Spota (1980) comenta que: "Quizá en el futuro -siguiendo a Babiloni y a códigos extranjeros contemporáneos (...)- habría que establecer que todas las veces que nos obligamos a conferir o transmitir un derecho patrimonial a otro adquiere a título oneroso, existe compraventa o permuta" (p. 29).

Por su parte, Albaladejo (1980) nos dice que pueden ser objeto de venta las cosas o derechos, aunque en la práctica sea más frecuente la de aquellas (del derecho de propiedad sobre las mismas). Los derechos vendibles serán, en principio, los patrimoniales de 
cualquier tipo: así, reales (como un usufructo), sobre bienes inmateriales de crédito, etc., salvo que sean intransferibles. $Y$ con respecto a los requisitos que deben cumplir nos dice que, según las reglas generales, la prestación ha de ser posible, lícita y determinada o determinable (pp. 17 y 18).

Explica Ferri (2002) que: "Evidentemente, el concepto de bien no puede seguir siendo entendido en la limitada acepción de "cosa" (parte separada de la realidad material), que deriva de la definición contenida en el artículo 810 del cód. civ. (Italiano); debe entenderse, más bien, en un sentido más amplio, que comprenda todos aquellos valores acostumbradamente, pero no exclusivamente (...), económicos (las actividades, las llamadas cosas "incorporales", y los derechos mismos) que pueden constituir el punto de referencia objetivo de un interés" (p. 278).

En cuanto a la doctrina nacional, en opinión de AriasSchereiber (1996), siguiendo a Valencia Restrepo, el objeto de la compraventa, ordinariamente está determinado por cosas o bienes corporales, pero nada impide que sean incorporales o derechos que formen parte de ella y que se puedan vender por separado, como los universales, intelectuales y personales. Todo bien que pueda venderse. No sólo los que existan sino también los que puedan existir, pero que ambas sean comerciables y posibles de determinar, al menos en su género, pues la cantidad puede ser incierta pero el contrato fijará reglas para poderlas determinar. Serán comerciables, cuando estén en el tráfico económico jurídico, debe ser un bien económico (cosa útil o escasa o que implique trabajo humano), y un bien jurídico (cosa útil y apropiable). Ahora, si el objeto es un hecho, será necesario que este sea física y moralmente posible, es decir será físicamente imposible el que es contrario a la naturaleza, y moralmente imposible el que va contra las leyes, las buenas costumbres o el orden público. Consiguiente pueden venderse todas las cosas corporales o incorporales o de las cuales se puedan ejercer derechos patrimoniales o enajenables: los derechos personales, los derechos intelectuales y los derechos universales (pp. 23-24).

Apunta De La Puente (1999) que: "Debe entenderse que cuando el Código Civil Peruano habla de transferencia de la propiedad de un bien se está refiriendo a la propiedad de una cosa (bien corporal) o de un derecho (bien incorporal), y que cuando habla del bien materia de la venta se está refiriendo al derecho de propiedad sobre una cosa o sobre un derecho" (p. 38).

Finalmente, Vidal (1998) considera que "el objeto, cuando es material o inmaterial es un bien, pero cuando solo es material es una cosa" (p. 121).

El concepto del "bien" en la compraventa es un tema amplio para discutir y tiene muchas aristas que la doctrina ha tratado extensamente, pero que no es el propósito de nuestro trabajo. No obstante, hemos querido mostrar algunas de estas posiciones doctrinarias, a fin de ubicar la marcada tendencia doctrinaria a considerar dentro del concepto de "bien" a la "cosa". En el caso de nuestro Codificador se ha escogido el término de "bien" para designar al objeto del contrato de compraventa que, según hemos visto, estaría referido tanto a las cosas (bienes corporales) como los derechos (bienes incorporales) que sean determinados o determinables, posibles de existir y comerciables. Efectivamente el art. 1532 del Código civil peruano establece que: "Pueden venderse los bienes existentes o que puedan existir, siempre que sean determinados o susceptibles de determinación y cuya enajenación no este prohibida por ley".

Asimismo, esta tendencia a incluir dentro del concepto de "bien" a la "cosa" habría sido una de las razones por las que se dejó de utilizar el contrato de cesión de créditos y dar paso a la cesión de créditos como figura obligacional cuya definición según el Código civil peruano parece sólo aludir a los derecho de crédito y no a todos los derechos. Efectivamente, bajo la definición del Código civil peruano el art. 1206 considera que: "La cesión es el acto de disposición en virtud del cual el cedente transfiere al cesionario el derecho a exigir la prestación a cargo de su deudor, que se ha obligado a transferir por un título distinto".

Por otro lado, el Artículo 1215 del mismo Código dispone que "La cesión produce efecto contra el deudor cedido desde que éste la acepta o le es comunicada fehacientemente". Es decir, tal como lo manifiesta López de Zavalía (1985), la cesión se limitaría a transferir situaciones jurídicas activas preexistentes, mientras que la compraventa podría crear una nueva situación jurídica real (p. 18).

En ese orden de ideas, por ejemplo, no se podrían aplicar dichos artículos para la constitución de una servidumbre personal, ya que al no existir una relación obligacional en fase de ejecución, no habría un deudor ni un acreedor, por tanto, el tercero (cesionario) no ingresaría a ocupar el lugar del acreedor originario (cedente) ni habría un deudor (cedido) a quien notificar la transferencia de dicho derecho. Además, la constitución de una servidumbre personal (usufructo, uso, habitación), supone una desmembración que puede verificarse per traslatione, (transmitiendo el goce y reservando la nuda propiedad) o per deductionem (trasmitiendo la nuda propiedad y reservando el derecho de goce), pero ni en uno ni en otro caso, tiene nada que hacer la cesión y el instrumento idóneo, como título, sería la compraventa (López de Zavalía (1985) p. 18).

De opinión similar es Lorenzetti (2004), al considerar que el cedente debe transmitir la propiedad del crédito 
al cesionario con el contenido que el crédito tenía, lo que es una aplicación de la regla de que nadie puede transmitir un derecho más extenso que el que tiene. La cesión importa una subrogación legal del crédito, el que se transmite con todas sus cualidades y con todos sus defectos, desventajas, cargas, restricciones y vicios que tuviere. Por esta razón, el deudor puede oponer al cesionario todas las defensas fundadas en el crédito que importan restricciones al mismo o cargas, como la suspensión del incumplimiento, la resolución, la simulación, fraude, dolo, etc. (pp. 42 y 43 ).

En esta línea, De la Puente y Lavalle, ponente del articulado actual, señalaba que la cesión es un acto jurídico cuya finalidad es establecer el modo como se transmiten los derechos que han sido adquiridos o transferidos en virtud de título distinto, bien sea contractual, como el caso de la compraventa, la permuta o la donación de derechos, o bien extracontractual, como en el caso de la herencia o una disposición legal (Osterling et al. (1994) p. 476). Ello sería posible, por cuanto el artículo 1529 del Código civil peruano, al definir la compraventa se refiere a la transferencia de la propiedad de un bien, concepto que comprende tanto a la cosa como el derecho, cuidando el artículo 1206 de precisar que la cesión es el acto de disposición en virtud del cual el cedente transfiere al cesionario el derecho a exigir la prestación a cargo de su deudor, que se ha obligado a transferir por un título distinto (De la Puente (1996) p. 38).

\section{Cesión como modo}

Al referirnos en el capítulo anterior al articulado actual del Código Civil peruano y preguntarnos si estamos ante una cesión de créditos o una cesión de derechos, citamos a De la Puente (1996), quien entendía a la cesión como un acto de disposición. Así, el mismo autor declaraba:

"También en puridad y aplicando la teoría del título y el modo que informa el Código Civil peruano, tratándose de la compraventa de una cosa, el contrato de compraventa es el título de adquisición y la entrega (cosas muebles) o la concurrencia del artículo 949 del Código Civil (cosas inmuebles) es el modo de adquirir, y tratándose de la compraventa de un derecho, el contrato de compraventa es el título de adquisición y la cesión de derechos contemplada en el artículo 1206 del Código Civil es el modo de adquirir" (p. 38).

Entonces, para este autor, el título, sería cualquier contrato con función traslativa (Ejm: Compraventa, donación, permuta, etc.) y el modo, la cesión del artículo 1206.

Como sabemos, los sistemas de transmisión del dominio inmobiliario responden a categorías generales de acuerdo a la dependencia o independencia de las causas en ellos involucradas (Fernández (1994)). Así, tenemos principalmente: el Sistema de la Unidad del Contrato y el Sistema de la Separación del Contrato.

El primero, se divide en el Sistema Transmisivo de la Causa Única, que es un sistema netamente espiritualista, en este sistema el contrato tiene efectos reales, es decir el contrato no crea obligaciones sino tiene un efecto real, es decir el solo consentimiento de las partes es causa suficiente para transferir el derecho real al nuevo propietario y, por otro lado, el Sistema Transmisivo de la Doble Causa, que incluye el Sistema Real o de Tradición o Sistema de la Unión del Título y del Modo, y el Sistema Registral Constitutivo No Convalidante o Causal, en este sistema el acto de obligación y el acto de disposición dependen uno de otro, el contrato no tiene efectos reales, sólo crea obligaciones, por lo que es necesario de un acto de disposición para terminar de transferir la propiedad de un bien. Entonces, si existiese un vicio de validez en el acto obligacional o contrato, el posterior acto de inscripción en el registro también resultaría inválido, ya que el acto de obligación es la causa del acto de disposición, consecuentemente no se habría producido la transferencia del derecho de propiedad sobre el bien.

El segundo, el Sistema de la Separación del Contrato, es un Sistema Transmisivo de Causa Abstracta, es decir implica el Sistema Registral Constitutivo Convalidante -en este caso, el acto de obligación y el acto de disposición son independientes, por lo que si el acto obligacional o contrato fuese inválido, no afectaría el acto del registro, que podría resultar plenamente válido y eficaz. En este sistema se produce la convalidación de los defectos estructurales y funcionales del acto obligacional con el acto de inscripción registral, ya que el acto de disposición se abstrae del acto de obligación, consecuentemente el adquiriente continuará siendo el propietario del bien- y el Sistema Real Abstracto (Larenz (1957) p. 27).

Como lo expresa De La Puente (1994), el régimen legal peruano habría optado por el Sistema de la Unidad del Contrato en la modalidad de Yuxtaposición de los Principios de la Unidad y la Tradición (título y modo). En este caso además del contrato con finalidad traslativa, se requiere la concurrencia de un acto jurídico adicional: la entrega del bien o la inscripción del contrato en el Registro. Aquí, aquél, sirve de título para la adquisición, mientras éstos dos fungen de modos), es decir el título es un acto de obligación, en virtud del cual surge la obligación de transferir la situación subjetiva y el modo es el acto de disposición, en virtud del cual se transfiere la situación subjetiva. Al respecto, en opinión del mismo autor, la razón para que sea preferible el sistema que exige el perfeccionamiento del acto dispositivo, ora la tradición de la cosa (para muebles), ora esta misma, o la 
inscripción en el registro respectivo (para inmuebles), citando a León Barandiarán, al comentar el artículo 1172 del Código civil peruano de 1936, “... estriba en el propio carácter del acto que entraña transferencia de dominio. A diferencia del derecho personal, relativo únicamente a las personas del acreedor y del deudor, el derecho real tiene un valor absoluto, pues es eficaz erga omnes. Luego es preciso un hecho notorio o de publicidad -la posesión de la cosa por el adquirente mediante la tradición, o la inscripción del acto en el registro respectivo- para que el derecho adquirido pueda merecer el respeto del tercero. Tal consideración fue la que tuvo presente el legislador alemán (Chalemel)" (p. 14).

La teoría del título y el modo habría sido construida - elaborada, en realidad, en base a las ideas de posibilidad y efectividad. La posibilidad, o sea el contrato de transferencia, sería llamada causa remota, y el medio efectivo de concretar la transmisión, sería llamado causa próxima. A la causa remota se le llamaría, a su vez, titulo de adquisición y a la causa próxima se le llamaría modo de adquirir. Por estas razones el sistema peruano de transmisión convencional de la propiedad de todos los bienes determinados, sean muebles o inmuebles, habría optado por la teoría del título y el modo que requeriría la indispensable conjunción de un acuerdo de voluntades orientado a transferir la propiedad y de un medio que permita lograrlo. En el caso de los bienes muebles determinados, el título estaría constituido por el respectivo contrato de transferencia y el modo, por la tradición, en aplicación del artículo 947 del Código civil peruano. En el caso de los bienes inmuebles determinados, el título estaría también constituido por el respectivo contrato de transferencia y el modo por la aplicación del artículo 949 del mismo Código.

A este respecto De La Puente (1994), recordando los antecedentes de la elaboración del Código civil peruano de 1984, cuyo primer Proyecto clasificaba los bienes en registrados y no registrados, afirma que aquel codificador optó claramente desde el principio por el régimen de la teoría del título y el modo, en el cual la tradición era el modo de adquisición de los bienes no registrados y la inscripción el modo de adquisición de los bienes registrados, requiriéndose en ambos casos la existencia de un contrato de transferencia que sirva de título. El cambio efectuado en el segundo Proyecto respecto a la clasificación de los bienes en muebles (en sustitución de los bienes no registrados) e inmuebles (en sustitución de los bienes registrados) no estuvo orientado a modificar el régimen de transmisión convencional de la propiedad de los bienes, tanto es así que se conservó el efecto exclusivamente obligacional del contrato, sino evitar los peligros que representaba la ineficiencia de nuestros Registros Públicos. Sin embargo, como este cambio de clasificación dejaba en el aire el tratamiento de la adquisición de la propiedad de los bienes inmuebles, se recurrió a la regla contenida en el artículo 1172 del Código civil peruano de 1936, según la cual la sola obligación de dar una cosa inmueble determinada hace al acreedor propietario de ella, olvidando que ella estaba ubicada en el Libro del Derecho de Obligaciones y no en el Libro de Derechos Reales (pp. 12 y 13).

Consecuentemente, el contrato en general (incluidos los contratos de transferencia de la propiedad) tendría efectos exclusivamente obligacionales, esto es, se limitaría a crear una relación jurídica compuesta de obligaciones, y no podría, por sí solo, tener efectos reales, pues para ello requeriría adicionalmente un modo de constituir el derecho (De La Puente (1994) pp. 9-16).

A este respecto, López de Zavalía (1985) explica que el sistema romano reposaba sobre la distinción entre título y modo. La compraventa era título, es decir acto que por sí solo no transmite el dominio, pero que sirve mediatamente para ello, al explicar y justificar el modo, dándole razón de ser. Por su parte, en el ordenamiento de su país, la compraventa verifica una atribución creditoria obligando a cumplir con el modo, el vendedor está obligado a transmitir el dominio, en tanto que en el derecho romano sólo estaba obligado a vacuam possessionem tradere (el vendedor no estaba obligado a transmitir la propiedad, pero lo estaba en hacer todo lo posible para que la propiedad se transmita). Entonces, la compraventa romana no verificaba una atribución real; es decir, por el solo hecho de la compraventa, el comprador no adquiría ningún derecho real, esa sería la sustancia de la teoría del título y el modo, con el modo solo, no se adquiere el dominio.

Para la atribución de la propiedad los romanos distinguieron originalmente según que las cosas fueran mancipi o nec mancipi, asignando para las primeras, como modo, la mancipatio -que sería un negocio jurídico formal porque exige el cumplimiento de ciertas solemnidades, como la presencia de cinco testigos y la intervención del librepens, y abstracto porque opera la transmisión de la propiedad independientemente de la validez del negocio causal que la explica, y que puede ser variado, por ejemplo, una compraventa o una donación- y la in iure cesio -que sería un modo formal y abstracto, que sustancialmente consiste en un proceso fingido de reivindicación ante el pretor que sirva tanto para las cosas mancipi como para las nec mancipi, pero no para los fundos provinciales-, y para las segundas, la traditio; pero con el andar del tiempo cayeron en desuso los dos primeros modos, y la traditio se convirtió en general apto para la transmisión de la propiedad de cualquier clase de cosas, tanto mancipi como nec mancipi (pp. 28 y 29). Es por esto, que la venta de bienes muebles del derecho argentino se rige por el sistema romano del título y el modo, siendo 
la compraventa el título y la tradición el modo. En la venta de inmuebles se conserva también el sistema romanista que exige el sistema del título y el modo, pero este último habría sido mutilado de tal manera que sólo sirve para hacer adquirir el dominio respecto al vendedor, mientras que para hacer adquirir el dominio erga omnes haría falta además, la inscripción. De allí habría nacido la distinción entre título y modo (pero modo mutilado) y medio (o forma) de publicidad. Con arreglo a ello, la compraventa sería título, la tradición sería modo (mutilado) y la inscripción sería medio (pp. 32 y 33$)$.

En el Derecho Español el régimen legal es descrito por Ruíz Serramalera (1981)

"Adopta nuestra legislación en materia de adquisición derivativa por contrato de los derechos reales, el sistema romanista inspirado en la teoría del título y del modo, según el cual la propiedad o cualquier otro derecho real no se adquieren sino por la concurrencia de dos requisitos esenciales: por una parte, la causa jurídica de la adquisición -llamada título-, y por otra parte, la transmisión efectiva de la posesión de la cosa o tradición -denominada modo- si faltare cualquiera de estos requisitos no se produce la adquisición del derecho, pues por el contrato (título) sólo origina un vínculo obligacional, dirigido en estos casos, precisamente a la entrega de la cosa (contenido de la prestación), y el modo (tradición) no es suficiente tampoco para la validez y eficacia de los negocios jurídicos, sino que es preciso que la entrega tenga un fundamento anterior, sin el cual solo se produce como máximo, el nacimiento de la posesión, (por ser resultado únicamente de una situación de hecho).

En nuestra legislación, por lo tanto, hay que distinguir cuando la adquisición de la propiedad o de los demás derechos reales se realice a través de un contrato, dos momentos distintos de los que surgen, respectivamente, un derecho de crédito (a la entrega de la cosa) y un derecho real (sobre la misma cosa), estando condicionado el nacimiento de este último a la validez del título traslativo y a la realidad de la tradición o de la entrega" (p. 29).

Si bien queda claro que en el derecho español se ha consagrado la teoría del título y el modo, no queda claro por qué en el art. 1473 del Código civil español se indica que:

"Si una misma cosa se hubiese vendido a diferentes compradores, la propiedad se transferirá a la persona que primero haya tomado posesión de ella con buena $\mathrm{fe}$, si fuere mueble. Si fuere inmueble, la propiedad pertenecerá al adquirente que antes la haya inscrito en el registro. Cuando no haya inscripción, pertenecerá la propiedad a quien de buena fe sea primero en la posesión; y, faltando ésta, a quien presente título de fecha más antigua, siempre que haya buena $\mathrm{fe}^{\prime \prime}$; lo que en nuestra opinión, resulta una grave contradicción al sistema de transferencia basado en la doble causa (título y modo), ya que en el citado articulado claramente se indica que "la propiedad se transferirá", faltando la inscripción o la tradición del bien inmueble, a la persona que "presente título de fecha más antigua"; es decir, que bastará el simple título (causa remota o acto de obligación) para transferir la propiedad del inmueble, sin que sea necesario el "modo" (causa próxima o acto de disposición); es decir, que siendo consecuentes con la teoría del "título y el modo", un simple contrato de efectos obligacionales (título) no sería suficiente para transferir la propiedad hasta que se realice el "modo. Así, en el caso de una compraventa, el comprador, al momento de la suscripción del contrato, sólo sería el acreedor del bien; es decir, sólo sería titular de un derecho personal (derecho de crédito). El contrato de compraventa, que es un simple "título", no sería suficiente para otorgarle al comprador la titularidad del derecho propiedad sobre el bien (derecho real) hasta que se realice la tradición o la inscripción registral; es decir, se realice el "modo" que lo convierta en el nuevo propietario.

En el caso de la cesión de créditos, según Lorenzetti (2004), el cedente se obliga a transmitir al cesionario el derecho que le compete contra el deudor, entregándole el título de crédito, si existiese. Habiendo calificado a este contrato como consensual o bilateral debemos admitir que el cedente tiene una obligación de ceder, cuyo contenido es distinto según se otorguen efectos traslativos al mero consentimiento o no. El mismo autor, citando a Diez Picazo, afirma que la cesión presenta dos aspectos: el acto que la causa y el acto traslativo.

En un sentido técnico preciso, la cesión corresponde a este segundo momento, y siendo traslativo puede responder a causas diversas, pero ello no significa que la cesión sea un acto abstracto como han pretendido algunos autores. Es así que debe haber coincidencia entre la causa negocial y la traslativa, por ello se hace referencia a la cesión-venta, la cesión-permuta, la cesión- donación, etc. La cesión debe responder, entonces, a una causa con aptitud para configurar la transferencia de un derecho. De la regla antes dicha se desprende que las partes pueden plantear defensas fundadas en la falta de causa, su ilicitud, simulación, o ineficacia (p. 40).

Si es cierto que el Código Civil peruano, al igual que los ordenamientos citados, ha optado por el sistema del título y el modo; entonces, como textualmente dice el artículo 1206: "la cesión es el acto de disposición en virtud del cual el cedente transfiere al cesionario el derecho a exigir la prestación a cargo de su deudor, que se ha obligado a transferir por un título distinto" 
haría falta de un título, que deberá ser el acto de obligación o contrato, causa del acto de disposición, para que la transferencia del derecho de crédito se produzca.

Volviendo a la opinión de De La Puente (1996), citada al inicio de este capítulo, para la transferencia de una cosa, el contrato de compraventa sería el título de adquisición y la entrega (en el caso de las cosas muebles) o la concurrencia del artículo 949 del Código civil peruano (en el caso de las cosas inmuebles) sería el modo de adquirir, y tratándose de la compraventa de un derecho, el contrato de compraventa sería el título de adquisición y la cesión de derechos contemplada en el artículo 1206 del Código civil peruano el modo de adquirir, entonces tendríamos que, al igual que el mandato del 949, el contenido del artículo 1206 vendría a establecer el acto de disposición, es decir el modo que terminaría de transferir la propiedad de un derecho de crédito (p. 38).

Pero el problema es determinar en qué consiste concretamente ese acto de disposición, que hemos visto estriba en el propio carácter del acto que entraña transferencia de dominio, que debería implicar un comportamiento notorio o de publicidad para que el derecho adquirido pueda merecer el respeto de terceros y que justamente está presente en el caso del artículo 949 del Código Civil peruano. Efectivamente, como lo manifiesta Forno (1993), si la obligación consiste en transmitir el derecho de propiedad y ese efecto, según el artículo 949 del código se logra mediante la sola obligación de enajenar, esa obligación sería absolutamente inútil pues no puede darse siquiera la secuencia de obligación y cumplimiento ya que el pago de tal obligación se produce, con independencia de toda actividad del deudor, por el hecho de su misma existencia; ella se paga por sí misma, es su propio cumplimiento, citando el mismo autor a Bianca considera, además, que es una artificiosa construcción que consiste en una obligación que se extingue al mismo tiempo en que surge; una obligación, en definitiva, desprovista de toda pretensión crediticia. Es una paradoja inexplicable: la propia obligación significa cumplimiento de sí misma. La conclusión es pues, que el contrato produce directamente la atribución del derecho de propiedad (p.86).

A diferencia de nuestra codificación, en aquellos ordenamientos que consagran la cesión de derechos, identifican un modo concreto para la cesión de créditos personales, así por ejemplo, el Código civil chileno en el artículo 1901 establece que "la cesión de un crédito personal, a cualquier título que se haga, no tendrá efecto entre el cedente y el cesionario sino en virtud de la entrega del título". Esto, independientemente de la notificación que debe hacerse al deudor (cedido), pues el artículo 1902 del mismo Código indica que "la cesión no produce efecto contra el deudor ni contra terceros, mientras no ha sido notificada por el cesionario al deudor o aceptada por éste". Incluso, en dicho acto de notificación debe estar presente la transferencia del título, tal como lo indica el artículo 1903: "la notificación debe hacerse con exhibición del título, que llevará anotado el traspaso del derecho con la designación del cesionario y bajo la firma del cedente".

Por su parte, el antiguo Código Civil argentino en el artículo 1434 establecía que "habrá cesión de crédito, cuando una de las partes se obligue a transferir a la otra parte el derecho que le compete contra su deudor, entregándole el título del crédito, si existiese". Esto, independientemente de la notificación que debe hacerse al deudor (cedido), pues el artículo 1467 del mismo código indicaba que "la notificación y aceptación de la transferencia, causa el embargo del crédito a favor del cesionario, independientemente de la entrega del título constitutivo del crédito, y aunque un cesionario anterior hubiese estado en posesión del título; pero no es eficaz respecto de otros interesados, si no es notificado por un acto público". Por su parte, el actual Código civil y comercial de la nación establece en el artículo 1619 que "el cedente debe entregar al cesionario los documentos probatorios del derecho cedido que se encuentren en su poder. Si la cesión es parcial, el cedente debe entregar al cesionario una copia certificada de dichos documentos". En cuanto a la oponibilidad frente a terceros, el artículo 1620 del mismo cuerpo legal establece que "la cesión tiene efectos respecto de terceros desde su notificación al cedido por instrumento público o privado de fecha cierta, sin periuicio de las reglas especiales relativas a los bienes registrables".

Finalmente, el primer párrafo del artículo 1526 del Código civil español establece que "la cesión de un crédito, derecho o acción no surtirá efecto contra tercero sino desde que su fecha deba tenerse por cierta en conformidad a los artículos 1218 y 1227". En el segundo párrafo del mencionado artículo indica que "si se refiere a un inmueble, desde la fecha de su inscripción en el Registro".

A este respecto Cuadrado Pérez, siguiendo a Pantaleón, comenta que: "En el Derecho español no cabe contemplar la cesión de créditos como un negocio dispositivo abstracto, independiente de los negocios de obligación causales en los que pueda fundarse. Como atinadamente advierte este autor, si, como ocurre en el Derecho alemán, el sistema de las transmisiones patrimoniales o adquisiciones derivativas inter vivos se rigiera en nuestro ordenamiento por el Trennungsprinzip (principio de separación de dos negocios jurídicos diversos en los hechos adquisitivos: uno de obligación y otro de disposición) y su correlato lógico el Abstraktionsgrundsatz (principio de abstracción que determina que la validez y eficacia 
del negocio de disposición resulta independiente de las del negocio de obligación en el que aquél se cimienta), cabría configurar la cesión de créditos como un negocio de disposición abstracto distinto e independiente de los negocios de obligación causales en los que pueda fundarse. Si así fuera, consistiría en la concorde voluntad de las partes, cedente y cesionario, de transmitir y adquirir la titularidad del crédito.

Sin embargo, en el ordenamiento jurídico español, el sistema de las transmisiones patrimoniales o adquisiciones derivativas inter vivos se halla dominado por el "dogma de la causalidad", de tal modo que es preciso un negocio jurídico verdadero y válido en aras a producir una transmisión patrimonial (de derechos reales o de crédito), y que sea legalmente suficiente para transferir el derecho en cuestión (señala Pantaleón que podríamos llamar principio de la unidad, o Einheitsprinzip, como contraposición al ya mencionado Trennungsprinzip)" (Cuadrado Pérez, Carlos (2014) pp. 52 y 53 ).

A través de este análisis, ha quedado demostrado que en el sistema causalista es importante la existencia de un acto de obligación causal en el que pueda fundarse el acto de disposición posterior. Es decir, si el acuerdo o acto jurídico no es válido, la cesión del crédito no sería eficaz. Si bien en nuestro ordenamiento, al igual que los ordenamientos analizados, ha quedado descartada la aplicación del sistema de separación del contrato por el cual la cesión de créditos se configura como un negocio de disposición abstracto distinto e independiente de los negocios de obligación causales en los que pueda fundarse. El problema que subsiste en nuestra legislación -que habría optado por el Sistema de la Unidad del Contrato en la modalidad de Yuxtaposición de los Principios de la Unidad y la Tradición (título y modo)- es que no queda claro cuál es el acto de disposición (modo).

\section{Concurrencia de cesionarios}

Otro tema interesante que deviene del análisis anterior, es el problema que se suscita cuando hay concurrencia de acreedores, que en el caso de la transferencia de la propiedad de cosas (bienes corporales), al haber optado, aparentemente, nuestro ordenamiento el sistema del título y el modo, debería prevalecer aquel comprador que adquirió realizando el acto de obligación y el acto de disposición válidamente, que en el caso de las cosas muebles sería la tradición ya que el artículo 947, que indica: "La transferencia de propiedad de una cosa mueble determinada se efectúa con la tradición a su acreedor, salvo disposición legal diferente". Lo que es concordante con lo previsto en el artículo 1136 que considera que: "Si el bien cierto que debe entregarse es mueble y lo reclamasen diversos acreedores a quienes el mismo deudor se hubiese obligado a entregarlo, será preferido el acreedor de buena fe a quien el deudor hizo tradición de él, aunque su título sea de fecha posterior. Si el deudor no hizo tradición del bien, será preferido el acreedor cuyo título sea de fecha anterior; prevaleciendo, en este último caso, el título que conste de documento de fecha cierta más antigua".

Y en el caso de las cosas inmuebles debería ser la inscripción registral, ya que en el artículo 1135 se establece que: "Cuando el bien es inmueble y concurren diversos acreedores a quienes el mismo deudor se ha obligado a entregarlo, se prefiere al acreedor de buena fe cuyo título ha sido primeramente inscrito o, en defecto de inscripción, al acrleedor cuyo título sea de fecha anterior. Se prefiere, en este último caso, el título que conste de documento de fecha cierta más antigua".

No obstante, anteriormente, hicimos referencia a un grave inconveniente en la redacción del artículo 949 del citado cuerpo legal, según el cual "la sola obligación de enajenar un inmueble determinado hace al acreedor propietario de él, salvo disposición legal diferente o pacto en contrario", que ha suscitado una interesante discusión doctrinaria entre quienes consideran que en este caso se habría dejado de lado el contrato con efectos obligacionales dando paso a un contrato con efectos reales (Forno (1993) pp. 77-87) y, otro sector doctrinario, que considera que estamos ante un contrato de efectos obligacionales (De La Puente (1994) pp. 9-16).

Como puede desprenderse, la falta de claridad en el legislador peruano hace inminente la complicación que surgirá al resolver un caso de concurrencia de acreedores en la cesión de créditos, por lo que resulta necesario explorar las soluciones propuestas por otros ordenamientos, como los principios de UNIDROIT donde el artículo 9.1.11 dispone que: "Si un mismo crédito ha sido cedido por el cedente a dos o más cesionarios sucesivos, el deudor se libera pagando conforme al orden en que las notificaciones fueron recibidas".

En sentido similar, el artículo III.-5:121(1) del DCFR (Draft Common Frame of Reference) también contempla esta hipótesis y ofrece una solución que dota de preferencia al cesionario que notificó antes su adquisición, siempre que en el momento de tal comunicación no conociera ni pudiera razonablemente esperarse que conociera que ese crédito había sido anteriormente transmitido. Como consecuencia de tal norma general, el cedente carecería del derecho a transmitir dicho crédito, de tal manera que los pretendidos cesionarios subsiguientes nada habrían adquirido, en aplicación del principio nemo dat quod non habet. Dicha opción de política legislativa asumida por el DCFR, según sus comentaristas (Study Group on a European Civil Code and Research Group on EC Private Law (Acquis Group)), reflejaría dos 
ideas distintas. La primera, que la notificación de la cesión de buena fe es el equivalente más cercano a la adquisición de la posesión de buena fe, que es un método contemplado para obtener prioridad en el caso de adquisición de bienes muebles corporales. La segunda, esta norma evidencia que quien pretenda ser cesionario puede previamente preguntar al deudor si ha recibido alguna notificación anterior sobre la cesión de dicho crédito. Entonces, si el primer cesionario no ha efectuado tal aviso, el segundo adquirente tendrá derecho a suponer que no ha existido una cesión anterior, a menos que dicho segundo cesionario haya tenido conocimiento de la existencia de la cesión anterior por alguna otra vía o debería haberla conocido, por ejemplo, porque se había procedido a su inscripción en un registro público (Cuadrado Pérez, Carlos (2014) pp. 62-65).

Por su parte, en el Código Civil peruano, el texto original del artículo 1217 que fue derogado por la Sexta Disposición Final de la Ley $N^{\circ} 28677$, Ley de la Garantía Mobiliaria, establecía que "si un mismo derecho fuese cedido a varias personas, prevalece la cesión que primero fue comunicada al deudor o que éste hubiera aceptado". Lo que era concordante con el vigente artículo 1215 del mismo cuerpo legal que dice: "la cesión produce efecto contra el deudor cedido desde que éste la acepta o le es comunicada fehacientemente". En la misma línea, el artículo 1216 establece que "el deudor que antes de la comunicación o de la aceptación, cumple la prestación respecto al cedente, no queda liberado ante el cesionario si éste prueba que dicho deudor conocía de la cesión realizada". Es decir, la notificación al deudor (cedido) no sería esencial para que la cesión tenga efectos, pues basta demostrar que éste (el deudor) tuvo conocimiento de la cesión para que tenga efectos entre las partes y frente a terceros.

En esta misma línea, los comentaristas del DCFR ponen de manifiesto que cuando ninguna de las partes ha dado aviso de la cesión del crédito, resulta aplicable la regla general prior tempore potior iure. No obstante, aclaran que la prioridad del primer cesionario es meramente provisional, ya que es susceptible de ser desplazado si el segundo adquirente, sin tener conocimiento de la anterior transmisión de dicho crédito, notifica al deudor la cesión del mismo antes de que lo haga el primer cesionario. Además, indican que el artículo III.-5:121 DCFR antes mencionado, no se aplica en el caso de las cesiones de créditos en garantía del pago de créditos dinerarios, pues sería incompatible con el sistema de inscripción para dicha garantía (Cuadrado Pérez, Carlos (2014) pp. 65-66).

Consecuentemente, en el Código Civil peruano, que aparentemente ha optado por el Sistema de la Unidad del Contrato en la modalidad de Yuxtaposición de los Principios de la Unidad y la Tradición (título y modo), no se puede afirmar que la notificación al deudor cedido sea el "modo" para transferir los créditos. No obstante, al tratar de buscar respuesta a este cuestionamiento, hemos visto que los comentaristas del DCFR consideran que la notificación de la cesión de buena fe es el equivalente más cercano a la adquisición de la posesión de buena fe, que es el método contemplado para obtener prioridad en el caso de adquisición de bienes muebles corporales, estableciendo un tratamiento especial a las cesiones de créditos en garantía de pago de créditos dinerarios donde prima el sistema de inscripción de dicha garantía.

Esta última tendencia, al parecer, habría sido utilizada para inspirar la derogación del artículo 1217 del Código civil peruano, antes mencionado, a través de la Sexta Disposición Final de la Ley № 28677, Ley de la Garantía Mobiliaria, que ha regulado en su artículo 27 el caso de la concurrencia de cesionarios con el texto siguiente: "La inscripción de la cesión de derechos en el Registro correspondiente, ya sea en propiedad o en garantía, otorga preferencia sobre su pago al cesionario desde la fecha de tal inscripción.

La cesión inscrita en el Registro correspondiente prevalece sobre la cesión notificada al deudor cedido. La cesión de derechos, ya sea en propiedad o en garantía, no es legalmente posible si ella está expresamente prohibida en el respectivo título".

Como vemos, el problema que se ha suscitado a raíz de la actual propuesta legislativa sobre concurrencia de cesionarios, independientemente que se transfieran derechos de crédito $u$ otros derechos, es que resulta mucho más difícil identificar cuál es el acto de disposición (el modo) en la cesión de créditos.

Efectivamente, al haberse derogado el artículo 1217 y estar aún vigente el artículo 1215 del Código civil peruano, que establece que la cesión produce efecto contra el deudor cedido desde que éste la acepta o le es comunicada fehacientemente, podría ocurrir que el cedente se haya obligado a ceder su derecho más de una vez, y el primer cesionario haya notificado la cesión al deudor (cedido) y el segundo cesionario haya inscrito su derecho en los Registros Públicos. Entonces, el cesionario que ha notificado al deudor (cedido) podría ampararse en lo regulado por el artículo 1215, argumentando que al haber hecho la notificación primero se ha convertido en el nuevo acreedor, por lo que las posteriores cesiones hechas por el acreedor originario (cedente) ya no son eficaces respecto al deudor (cedido).

Por su parte, quien sólo inscribió su derecho sin haber notificado, podría ampararse en el artículo 27 de la Ley de la Garantía Mobiliaria, que privilegia a quien ha realizado la inscripción primero, y que el deudor 
(cedido) ha tomado conocimiento de la cesión en virtud del principio de la publicidad registral establecido por el art. 2012 del Código civil peruano, al establecer que: "Se presume, sin admitirse prueba en contrario, que toda persona tiene conocimiento del contenido de las inscripciones". Lo que habría que concordar con el artículo 1216, al señalar que: "El deudor que antes de la comunicación o de la aceptación, cumple la prestación respecto al cedente, no queda liberado ante el cesionario si éste prueba que dicho deudor conocía de la cesión realizada". No obstante, en este caso habría que establecer cuál es el plazo prudencial para que se presuma dicho conocimiento por parte del deudor (cedido).

La otra posibilidad, sería entender que la intención del legislador es que, en el caso de la cesión de créditos, la inscripción es el modo o acto de disposición y que la notificación sólo es importante para darle eficacia respecto al deudor (cedido). Sin embargo, habrá derechos cuya inscripción no es posible por distintas razones y no tendremos cómo resolver el problema.

\section{CONCLUSIONES}

1. En el Código civil peruano de 1936 el contrato de cesión de créditos se confundía con otros contratos cuya función era transferir la titularidad de la propiedad de cosas: como la compraventa, la donacion o la permuta.

2. Cuando el Código Civil Peruano habla de transferencia de la propiedad de un bien se está refiriendo a la propiedad de una cosa (bien corporal) o de un derecho (bien incorporal), y que cuando habla del bien materia de la venta se está refiriendo al derecho de propiedad sobre una cosa o sobre un derecho.

3. El régimen legal peruano habría optado por el Sistema de la Unidad del Contrato en la modalidad de Yuxtaposición de los Principios de la Unidad y la Tradición (título y modo). Así, en el caso de una compraventa, el comprador, al momento de la suscripción del contrato, sólo sería el acreedor del bien; es decir, sólo sería titular de un derecho personal (derecho de crédito). El contrato de compraventa, que es un simple "título", no sería suficiente para otorgarle al comprador la titularidad del derecho propiedad sobre el bien (derecho real) hasta que se realice la tradición o la inscripción registral; es decir, se realice el "modo" que lo convierta en el nuevo propietario.

4. En el régimen legal peruano, para la transferencia de una cosa, el contrato de compraventa sería el título de adquisición y la entrega (en el caso de las cosas muebles) o la concurrencia del artículo 949 del Código civil peruano (en el caso de las cosas inmuebles) sería el modo de adquirir, y tratándose de la compraventa de un derecho, el contrato de compraventa sería el título de adquisición y la cesión de derechos contemplada en el artículo 1206 del Código civil peruano el modo de adquirir.

5. En el sistema causalista es importante la existencia de un acto de obligación causal en el que pueda fundarse el acto de disposición posterior. Es decir, si el acuerdo o acto jurídico no es válido, la cesión del crédito no sería eficaz. Si bien en nuestro ordenamiento queda descartada la aplicación del sistema de separación del contrato por el cual la cesión de créditos se configura como un negocio de disposición abstracto distinto e independiente de los negocios de obligación causales en los que pueda fundarse, el problema que subsiste en nuestra legislación -que habría optado por el Sistema de la Unidad del Contrato en la modalidad de Yuxtaposición de los Principios de la Unidad y la Tradición (título y modo)- es que no queda claro cuál es el acto de disposición (modo).

6. En el Código civil peruano, que aparentemente ha optado por el Sistema de la Unidad del Contrato en la modalidad de Yuxtaposición de los Principios de la Unidad y la Tradición (título y modo), no se puede afirmar que la notificación al deudor cedido sea el "modo" para transferir los créditos, ni que la misma cesión de créditos establecida en el artículo 1206 del mismo cuerpo legal sea el modo de adquirir.

\section{REFERENCIAS BIBLIOGRÁFICAS}

Albaladejo, Manuel (1980): Derecho Civil (Barcelona, Bosch) Tomo II, Vol. II.

Arias-Schereiber Pezet, Max (1996): Exégesis del Código Civil Peruano de 1984 (Lima, Gaceta Jurídica) Tomo II.

Borda, Guillermo A (1973): Manual de Contratos (Buenos Aires, Editorial Perrot).

Cuadrado Pérez, Carlos (2014) La Cesión de Créditos (Madrid, Editorial DYKINSON, S.L.).

De la Puente y Lavalle, Manuel (1996): El contrato de compraventa (Lima, Gaceta Jurídica Editores).

De La Puente y Lavalle, Manuel (1994): El contrato con efectos reales (Lima, Pucp) En: lus et Veritas. Año 5, No 9. Noviembre de 1994.

De la Puente y Lavalle, Manuel (1999): Estudios sobre el Contrato de Compraventa (Lima, Gaceta Jurídica Editores).

Diez Picazo, Luis y otro (1980) Sistema de Derecho Civil (Madrid, Editorial Temis) Segunda Edición., Vol. II. 
Fernández Cruz, Gastón (1994) La Obligación de enajenar y el sistema de transferencia de la Propiedad inmueble en el Perú (Lima, Pucp). En: Themis-Revista de Derecho №. 30.

Ferri, Giovanni Battista (2002) El Negocio Jurídico (Lima, Ara Ediciones).

Forno Flores, Hugo (1993) El contrato con efectos reales (Lima, Pucp) En: lus et Veritas. Año 4, No 7. Nov. de 1993.

Lete del Rio, José M (1990) Derecho de Obligaciones (Madrid, Editorial Tecnos S.A.)

Larenz, Karl (1957) Derecho de Obligaciones (Madrid, Editorial Revista de Derecho Privado) T. II.

López de Zavalía, Fernando (1985) Teoría de los Contratos (Buenos Aires, Víctor P. de Zavalía Editor) Tomo II, Parte Especial.

Lorenzetti, Ricardo Luís (2004) Tratado de los Contratos (Buenos Aires: Rubinzal-Culzoni) V.II.

Mazeaud, Henri, Jean y León (1959) Tratado de Derecho Civil (Buenos Aires, Ediciones Jurídicas Europa América) Tomo III, Vol III.
Osterling, Felipe y Castillo Freyre, Mario (1994) Tratado de Obligaciones (Lima, Pontificia Universidad Católica del Perú, Fondo Editorial) En: Para leer el Código Civil, Volumen XVI, Primera Parte, Tomo III.

Peirano Facio, Jorge (1997) Contratos. Montevideo (Ediciones del Foro S.R.L.) Tomo I.

Rezzónico, Luis María (1967) Estudio de Contratos en Nuestro Derecho Civil (Buenos Aires, Ediciones Depalma).

Ruiz Serramalera, Ricardo (1981) Derecho Civil (Madrid, Universidad Complutense. Facultad de Derecho. Servicio de Publicaciones).

Spota, Alberto G. (1980) Contratos (Buenos Aires, Ediciones Depalma) Vol. IV.

Study Group on a European Civil Code and Research Group on EC Private Law (Acquis Group).

Vidal Ramírez, Fernando (1998) El Acto jurídico (Lima, Gaceta Jurídica). 